\title{
Pengaruh Pembelajaran Matematika Dengan Media Audio Visual Dan Pendekatan Kontekstual Serta Minat Belajar Terhadap Kemampuan Pemahaman Matematik Siswa Kelas IV Sekolah Dasar
}

\author{
Eko Ismiyati ${ }^{1}$, Supriadi ${ }^{2}$, Sandra Sukmaning Adji ${ }^{3}$ \\ Universitas Terbuka, Indonesia ${ }^{1}$ \\ Universitas Pendidikan Indonesia, Indonesia ${ }^{2}$ \\ Universitas Terbuka, Indonesia ${ }^{3}$ \\ Email korepondensi: ekoismiyati1968@gmail.com/ supriadi.upiserang@upi.edu/ \\ sandra@ecampus.ut.ac.id
}

\begin{abstract}
ABSTRAK
Penelitian ini dilatarbelakangi oleh pentingnya kemampuan Matematis siswa. Model pembelajaran untuk meningkatkan kemampuan tersebut adalah model pembelajaran kontekstual dengan media audio visual. Desain penelitian yang digunakan dalam penelitian ini adalah Quasi Experimental Design dengan rancangan faktorial $2 \times 3$. Pengambilan sampel menggunakan teknik Cluster Random Sampling. Populasi dalam penelitian ini adalah seluruh siswa gugus 063 yang terdiri dari 14 Sekolah Dasar. Data dalam penelitian ini diperoleh dari hasil posttest kemampuan pemahaman matematis dan angket minat siswa. Pengolahan data dilakukan dengan menggunakan perhitungan anava dua arah dilanjutkan dengan uji lanjut (posthoc). Kesimpulan dari hasil pengolahan data adalah 1) Kemampuan pemahaman matematik siswa yang menggunakan media audio visual pembelajaran matematika dengan pendekatan kontekstual lebih tinggi dari pada siswa yang menggunakan pendekatan ekspositori.2) Pemahaman matematik siswa yang memiliki minat tinggi, sedang dan rendah yang menggunakan media audio visual pembelajaran matematika dengan pendekatan kontekstual lebih tinggi dari pada siswa yang menggunakan pendekatan ekspositori.3) Terdapat pengaruh interaksi antara pendekatan pembelajaran dan minat belajar siswa terhadap kemampuan pemahaman matematis.
\end{abstract}

Kata kunci: Pemahaman matematis, Kontekstual, Audio-visual, Minat belajar.

\section{ABSTRACT}

This research is motivated by the importance of students' mathematical abilities. The learning model to improve these abilities is a contextual learning model with audio-visual media. The research design used in this study is a Quasi Experimental Design with a $2 \times 3$ factorial design. Sampling using the Cluster Random Sampling technique. The population in this study were all students of the 063 cluster consisting of 14 elementary schools. The data in this study were obtained from the posttest results of mathematical understanding abilities and student interest questionnaires. Data processing was carried out using two-way ANOVA calculations followed by further tests (posthoc). The conclusions from the results of data processing are 1) The mathematical understanding ability of students who use audio-visual media for learning mathematics with a contextual approach is higher than students who use an expository approach. 2) Mathematical understanding of students who have high, medium and low interests who use audio-visual media Mathematics learning with a contextual approach is higher than 
students using an expository approach. 3) There is an interaction effect between the learning approach and students' interest in learning on the ability to understand mathematics.

Keywords: Mathematical understanding, Contextual, Audio-visual, Interest in learning.

\section{PENDAHULUAN}

Pembelajaran matematika khususnya di sekolah dasar menekankan pada pemberian pengalaman belajar secara langsung agar mampu mengembangkan kemampuan matematik secara optimal. Salah satu kemampuan yang sangat penting dalam belajar matematika yaitu kemampuan matematis. Kemampuan sangat penting untuk mencapai tujuan pembelajaran matematika yang optimal (Hikmah, 2017). Menurut Sari dkk., (2021) kemampuan matematis merupakan dasar dari kemampuan lainnya yang lebih tinggi seperti kemampuan komunikasi matematis dan berfikir kritis.

Permasalahan rendahnya kemampuan matematis tak jarang ditemui dalam pembelajaran matematika khususnya di tingkat sekolah dasar (D. P. Sari dkk., 2016). Pasalnya sifat matemtika yang abstrak berlawanan dengan tahap perkembangan anak usia sekolah dasar yang masih berada pada tahap operasional konkrit (Ibda, 2015). Anak-anak usia sekolah dasar pada tahap perkembangan intelektual tersebut lebih mudah dalam mempelajari konsep-konsep matematik yang abstrak melalui contoh-contoh konkrit yang berkaitan dengan kehidupan sehari-hari dan pengalaman langsung.

Rendahnya pemahaman konsep merupakan permasalahan yang sangat penting untuk ditemukan solusi penyelesaiannya, bahkan tidak berlebihan jika kemampuan pemahaman matematis yang rendah disinyalir turut mempengaruhi prestasi siswa secara keseluruhan. Agar siswa dapat memahami konsep matematika, pembelajaran matematika harus dapat memberikan kesempatan kepada siswa untuk mengkonstruksi konsep matematika melalui pengalaman nyata, sehingga siswa tidak hanya penuh dengan materi-materi matematika yang abstrak, tetapi juga pemahaman yang mendalam (Masitoh \& Prabawanto, 2016).

Model pembelajaran CTL merupakan salah satu model pembelajaran yang dapat membangun kemampuan diri secara aktif, mempelajari konsep sekaligus menerapkan dan mengaitkan dengan dunia nyata. Adim dkk., (2020) model pembelajaran kontekstual merupakan suatu model pembelajaran yang memberikan fasilitas kegiatan belajar siswa untuk mencari, mengolah, dan menemukan pengalaman belajar yang lebih bersifat nyata dengan melibatkan keaktifan peserta didik dalam mencoba, melakukan, serta mengalami sendiri. Proses pembelajaran model kontekstual dapat memberikan pengalaman bersifat konkrit dengan melibatkan keaktifan siswa, serta dapat menumbuhkan minat siswa untuk belajar. Melalui kegiatan pembelajaran yang menghadapkan konteks dunia nyata dan pengalaman langsung diharapkan pembelajaran matematika tidak hanya sebatas hafalan-hafalan rumus akan tetapi memperoleh pemahaman yang mendalam.

Hal yang tak kalah penting dalam belajar matematika, selain penggunaan model pembelajaran yang tepat yaitu minat belajar siswa. Karina, Syafrina, \& Habibah, (2017) menyatakan bahwa seseorang yang memiliki minat terhadap suatu aktivitas, akan memperhatikan aktivitas secara konsisten disertai rasa senang. Agar lebih efektif dalam penyampaian informasi dan menarik minat belajar siswa, model pembelajaran dapat dipadukan dengan media pembelajaran (Setiyani \& Pujiastutik, 2017). Media pembelajaran yang dapat dipadukan dengan model pembelajaran kontekstual agar dapat menarik minat belajar siswa yaitu media audio-visual. Sejalan dengan itu, Agustini dkk., (2021) mengungkapkan bahwa media audio visual merupakan media pembelajaran yang dapat menarik minat serta antusias siswa untuk mengikuti proses pembelajaran di sekolah, karena di dalam media audio visual ini 
menampilkan gambar- gambar, animasi, serta suara yang dapat menarik minat belajar bagi siswa.

Berdasarkan pemaparan di atas penelitian ini bermasud untuk mengungkap pengaruh pendekatan kontestual dengan media audio-visual dan minat belajar siswa terhadap kemampuan pemahaman matematis siswa kelas IV sekolah dasar. Pemebelajaran matematika dengan pendekatan kontekstual berbantuan media audio-visual diharapkan mampu meningkatkan minat belajar siswa serta pemahaman matematis siswa sekolah dasar

\section{METODE PENELITIAN}

Penelitian ini termasuk jenis penelitian kuasi eksperimen. Rancangan yang digunakan dalam penelitian yauitu $3 \times 2$ faktorial desain. Visual rancangan penelitian dapat dilihat pada tebel berikut ini:

Tabel 1. Factoroal Design

\begin{tabular}{|l|c|c|}
\hline Minat $(\mathrm{A})$ & $\begin{array}{c}\text { Pembelajaran Matematika dengan media audio } \\
\text { visual dan pendekatan kontekstual } \\
\text { (kelas eksperimen) }\end{array}$ & $\begin{array}{c}\text { Pembelajaran Matematika dengan } \\
\text { menggunakan pendekatan } \\
\text { Ekspositori } \\
\text { (kelas kontrol) }\end{array}$ \\
\hline Tinggi $\left(\mathbf{B}_{1}\right)$ & $\left(\mathrm{A}_{1} \mathrm{~B}_{1}\right)$ & $\left(\mathrm{A}_{2} \mathrm{~B}_{1}\right)$ \\
\hline Sedang $\left(\mathbf{B}_{2}\right)$ & $\left(\mathrm{A}_{1} \mathrm{~B}_{2}\right)$ & $\left(\mathrm{A}_{2} \mathrm{~B}_{2}\right)$ \\
\hline Rendah $\left(\mathbf{B}_{3}\right)$ & $\left(\mathrm{A}_{1} \mathrm{~B}_{3}\right)$ & $\left(\mathrm{A}_{2} \mathrm{~B}_{3}\right)$ \\
\hline
\end{tabular}

Keterangan:

$A_{1} B_{1}$ : Kelompok siswa yang belajar matematika dengan media audio visual dan pendekatan kontekstual dengan minat tinggi

$A_{1} B_{2}$ : Kelompok siswa yang belajar matematika dengan media audio visual dan pendekatan kontekstual dengan minat sedang

$A_{1} B_{3}$ : Kelompok siswa yang belajar matematika dengan media audio visual dan pendekatan kontekstual dengan minat rendah

$A_{2} B_{1}$ : Kelompok siswa yang belajar matematika menggunakan pendekatan ekspositori dengan mina tinggi

$A_{2} B_{2}$ : Kelompok siswa yang belajar matematika dengan pendekatan ekspositori dengan minat sedang.

$A_{2} B_{3}$ : Kelompok siswa yang belajar matematika dengan pendekatan ekspositori dengan minat rendah

Populasi dalam penelitian ini yaitu seluruh siswa kelas IV Sekolah Dasar Kecamatan Pasarkemis Kabupaten Tangerang. Teknik sampling menggunkan cluster random sampling sehingga dieroleh dua sekolah pada kelas IV yang akan ditetapkan sebagai kelas eksperimen dan kelas kontrol. Kelas Eksperimen diberikan perlakuan berupa model pembelajaran kontekstual dengan media audiovisual sedangkan kelas kontrol diberikan perlakuan berupa pendekatan ekpositori. Sebelum diberikan perlakuan masing-masing kelompok perlakuan dikategorikan terlebih dahulu berdasarkan minat belajar tinggi, sedang dan rendah. Teknik pengumpulan data yaitu menggunakan angket minat belajar siswa dan tes pemahaman matematik berupa uraian objektif. Berdasarkan rancangan penelitian maka teknik analisi data yang digunakan dalam penelitian ini yaitu analisis varians dua jalan dan dilanjutkan dengan uji post joc. Analisis data dilakukan dengan bantuan software SPP versi 25.

\section{HASIL DAN PEMBAHASAN PENELITIAN}


Hasil analisis data penelitian dimaksud untuk menjawab hipotesis penelitian yang telah ditentukan. Analisis data yang digunakan anova dua arah dan uji lanjut yang akan disajikan sebagai berikut:

Tabel 1. Rangkuman Analisi Varian Dua Jalan Tests of Between-Subjects Effects

\begin{tabular}{|c|c|c|c|c|c|}
\hline \multicolumn{6}{|c|}{ Tests of Between-Subjects Effects } \\
\hline Dependent Variable: & Pemahaman Matemat & & & & \\
\hline Source & $\begin{array}{c}\text { Type III Sum of } \\
\text { Squares }\end{array}$ & df & Mean Square & $\mathrm{F}$ & Sig. \\
\hline Corrected Model & $1418.327^{\mathrm{a}}$ & 5 & 283.665 & 11.597 & 0.000 \\
\hline Intercept & 236958.464 & 1 & 236958.464 & 9687.409 & 0.000 \\
\hline Metode & 140.170 & 1 & 140.170 & 5.730 & 0.021 \\
\hline Minat & 199.904 & 2 & 99.952 & 4.086 & 0.024 \\
\hline Metode * Minat & 882.913 & 2 & 441.457 & 18.048 & 0.000 \\
\hline Error & 1027.339 & 42 & 24.460 & & \\
\hline Total & 295102.000 & 48 & & & \\
\hline Corrected Total & 2445.667 & 47 & & & \\
\hline
\end{tabular}

Berdasarkan hasil analisis ANOVA dua jalur pada tabel 1 dengan taraf signifikansi 0.05 diperoleh bahwa:

a) Berdasakan hasil ANOVA dua jalur pada baris metode diperoleh nilai signifikansi sebesar $0.021<0.05$. Dengan kata lain terdapat perbedaan kemampuan pemahamn matemtik antara siswa yang diajar menggunakan media audio visual dengan pendekatan kontekstual dan siswa yang diajara menggunakan pendekatan ekspositori.

b) Pada baris minat diperoleh nilai signifikansi sebesar $0.024<0.05$, artinya terdapat perbadaan kemampuan pemahaman matematis berdasarkan katergori minat belajar tinggi, sedang dan rendah

c) Pada baris Minat diperoleh nilai dignifikansi sebesar $0.00<0.05$, secara statistik dapat dinyatakan terdapat pengaruh interaksi yang signifikan antara pendekatan pembelajaran dan minta belajar terhadap kemampuan pemahaman matematis.

Setelah diketahui adanya pengaruh interaksi yang signifikan, untuk mengetahui perbedaan rata-rata pada masing-masing kelompok sampel dilakukan uji lanjutan. Uji lanjutan dalam penelitian ini menggunakan teknik uji Tuckey. Hasil uji Tuckey dapat dilihat pada tabel 2. 
Tabel 2. Rangkuman Hasil Uji Komparasi Rerata Antar Kolom pada Masing-masing Kategori Minat Belajar

\section{Multiple Comparisons}

Dependent Variable: Pemahaman Konsep

Scheffe

\begin{tabular}{|c|c|c|c|c|c|c|}
\hline \multirow[t]{2}{*}{ (I) Minat } & \multirow[t]{2}{*}{ (J) Minat } & \multirow{2}{*}{$\begin{array}{c}\text { Mean } \\
\text { Difference (I-J) }\end{array}$} & \multirow[t]{2}{*}{ Std. Error } & \multirow[t]{2}{*}{ Sig. } & \multicolumn{2}{|c|}{ 95\% Confidence Interval } \\
\hline & & & & & Lower Bound & Upper Bound \\
\hline \multirow[t]{2}{*}{ Tinggi } & Sedang & 3.78 & 2.000 & 0.180 & -1.30 & 8.85 \\
\hline & Rendah & $6.84^{*}$ & 2.192 & 0.013 & 1.28 & 12.40 \\
\hline \multirow[t]{2}{*}{ Sedang } & Tinggi & -3.78 & 2.000 & 0.180 & -8.85 & 1.30 \\
\hline & Rendah & 3.06 & 1.640 & 0.188 & -1.10 & 7.22 \\
\hline \multirow[t]{2}{*}{ Rendah } & Tinggi & $-6.84^{*}$ & 2.192 & 0.013 & -12.40 & -1.28 \\
\hline & Sedang & -3.06 & 1.640 & 0.188 & -7.22 & 1.10 \\
\hline
\end{tabular}

Berdasarakan uji komparasi antar kolom, dengan taraf signifikansi 0.05 diperoleh bahwa:

a. Minat tinggi (i) dan sedang (j) memperoleh nilai signifikansi sebesar 0.180 artinya tidak terdapat perbedaan yang signifikan. Namun jika dilihat dari selisih rataannya yaitu sebesar 3.78 dan merupakan bilangan positif maka dapat dinyatakan bahwa kemampuan pemahaman matematis siswa dengan minat tinggi lebih baik dari pada siswa dengan minat sedang.

b. Minat tinggi (i) dan renadah (j) memperoleh nilai signifikansi sebesar 0.13 , dengan kata lain terdapat perbedaan yang signifikan. Berdasarkan selisih rataannya yaitu sebesar 6.84 maka dapat disimpulkan bahwa kemampuan pemahaman matematis siswa dengan minat tiggi lebih baik dari pada siswa dengan minat rendah

c. Minat sedang (i) dan minat rendah (j) memperoleh nilai signifikansi sebesar 0.188 , artinya tidak terdapat perbedaan yang signifikan. Namun berdasarkan selisih rataannya yaitu sebesar 3.06 dan merupakan bilangan positif maka dapat dinyatakan bahwa kemampuan pemahaman matematis siswa yang memilki minat sedang lebih baik dari pada siswa yang memiliki minat rendah.

Berdasarkan temuan penelitian diketahui bahwa terdapat perbedaan kemampuan matematis antara siswa yang diajar melalui pendekatan kontektual dengan media audiovisual dan pendekatan ekspositori. Perbedan tersebut ditunjukkan melalui hasil analisis varian dua jalan dengan nilai signifikansi sebesar $0.021<0.05$. Sedangkan berdasarkan perolehan rata-rata hasil tes pemahaman matematik siswa yang diajar melalui media audio vidual dengan pendekatan kontekstual yaitu 80.40 sedangkan pendekatan ekspositori yaitu 75.75.

Menurut Mulyasa (2010:57) CTL merupakan konsep pembelajaran yang menekankan pada keterkaitan antara materi pembelajaran dengan kehidupan siswa secara nyata, sehingga siswa mampu menghubungkan dan menerapkan apa yang dipelajarinya dalam kehidupan sehari-hari Konsep-konsep dalam pembelajaran CTL mempermudah guru dalam mengaitkan materi yang sedang dipelajari dengan konteks nyata. Muchlis (2008) pembelajaran CTL adalah konsep belajar yang membantu guru mengaitkan materi pembelajaran dengan situasi dunia nyata dan mendorong siswa membuat hubungan antara pengetahuan yang dimilikinya dengan menerapkannya dalam kehidupan sehari-hari.

Pembelajarn CTL dapat dipadukan dengan media pembelajaran seperti media audio visual sehigga lebih effektif penggunaannya dalam pembelajaran. Melalui media audio visual yang dipadukan dengan pembelajaran CTL memberikan peluang kepada guru untuk berimprovisasi dalam merancang kegiatan pembelajaran sehingga kegiatan pembelajaran yang dilaksanakan mampu menarik minat siswa dan mempermudah siswa dalam memahami materimateri yang diajarkan. Situasi kontekstual yang berkaitan dengan dunia anak yang disajikan 
pembelajaran kontekstual dipadukan dengan media audio visual mampu meningkatkan pemahaman konsep siswa terutama dalam belajar matematika. Berdasarkan uraian di atas dapat disimpulkan bahwa media audio visual dengan pembelajaran kontekstual dapat meningkatkan kemampuan pemahaman matematis siswa.

Perbedaan kemampuan pemahaman matematis antara siswa yang memiliki minat tinggi, sedang dan rendah pada peserta didik yang diajar menggunakan media audio visual dan pendekatan kontekstual dengan peserta didik yang di ajar menggunakan pendekatan ekspositori ditunjukkan melalui hasil analisis varians dua jalan dengan nilai signifikansi yang diperoleh yaitu sebesar $0.024<0.05$. Sedangankan untuk meihat perbedaan masing masing kelompok sampel berdasarkan kategori minat belajar dilihat melalui uji lanjut (psthoc). Hasil analisis data menggunakan uji lanjut menunjukan bahwa pada masing-masing kategori minat tinggi (i) dan sedang (j), Minat tinggi (i) dan rendah (j), Minat sedang (i) dan minat rendah (j) memperoleh nilai signifikansi secara berturut turut yaitu $0.180,0,130,0.188$ nilai tersebut lebih dari alpha 0.05 , dengan kata lain secara statistic dapat dinyatakan ada perbedaan yang signifikan.

Hasil belajar siswa tidak hanya ditentukan oleh faktor eksternal seperti pendekatan pembelajaran atau strategi pembelajaran yang digunakan akan tetapi dipengaruhi faktor lain seperti faktor internal. Salah satu faktor internal yang turut mempengaruhi kemampuan pemahaman matematis siswa yaitu minat belajar. Mulyasa (2013) berpendapat bahwa minat merupakan kecenderungan untuk melakukan suatu perbuatan, misalnya minat untuk mempelajari sesuatu. Menurut Syah (2011:133), keinginan yang besar pada sesuatu merupakan pengertian dari minat (interest). Kaitannya dengan pembelajaran, siswa yang memilki minat yang tinggi terhadap mata pelajaran yang sedang dipelajarinya maka akan lebih mudah memahami materi serta antusias mengikuti kegiatan belajar mengajar. Berdasarkan pemaparan di atas dapat disimpulkan bahwa minat belajar turut mempengaruhi kemampuan pemahaman matematis siswa semakin tinggi minat siswa semakin baik pula kemampuan pemahaman matematis.

Pengaruh interaksi antara pendekatan pembelajaran dan minat belajar terhadap kemampuan pemahaman matematis dinyatakan melalui hasil ANAVA dua jalur dengan perolehan nilai signifikansi sebesar $0.000<0.05$, artinya terdapat pengaruh interaksi antara pendekatan pembelajaran dan minat belajar terhadap kemampuan pemahaman matematis siswa.

Kemampuan pemahaman matematis merupakan hasil belajar yang lebih tinggi dari pada ingatan. Menurut Purwanto (2008:44) "pemahaman adalah tingkat pengetahuan di mana siswa mampu memahami konsep, situasi dan fakta yang diketahuinya". Kemampuan pemahaman matematis dipengaruhi oleh beberapa faktor baik eksternal maupun internal. Faktor eksternal yang mempengaruhi kemampuan pemahaman matematis yaitu pendekatan pembelajaran sedangkan faktor internal yang mempengaruhi kemampuan pemahaman matematis yaitu minat belajar siswa. Berdasarkan informasi kualitatif dan kuantitatif maka dapat disimpulkan bahwa terdapat pengaruh interaksi antara metode pembelajaran dan minat belajar terhadap kemampuan pemahaman matematis. 


\section{KESIMPULAN}

Berdasarkan hasil penelitian dan pembahasan maka dapat ditarik beberapa kesimpulan penelitian sebagai berikut:

1. Kemampuan pemahaman matematik siswa yang menggunakan media audio visual pembelajaran matematika dengan pendekatan kontekstual lebih tinggi dari pada siswa yang menggunakan pendekatan ekspositori.

2. Pemahaman matematik siswa yang memiliki minat tinggi, sedang dan rendah yang menggunakan media audio visual pembelajaran matematika dengan pendekatan kontekstual lebih tinggi dari pada siswa yang menggunakan pendekatan ekspositori.

3. Terdapat pengaruh interaksi antara pendekatan pembelajaran dan minat belajar siswa terhadap kemampuan pemahaman matematik.

\section{DAFTAR PUSTAKA}

Adim, M., Herawati, E.S.B., \& Nuraya, N., (2020), Pengaruh Model Pembelajaran Contextual Teaching and Learning (CTL) Menggunakan Media Kartu Terhadap Minat Belajar IPA Kelas IV SD

Anwar, Pujiastuti, dan Mutaqin (2019). Pengaruh Contextual Teaching and Learning dan Self Regulated Learning Terhadap Kemampuan Koneksi M

Arief S. Sadiman, dkk, (2007), Media Pendidikan: Pengertian, Pengembangan, dan Pemanfaatannya, Jakarta: PT Raja Grafindo Persada.

Arisah (2018). Penerapan Model Pembelajaran Contextual Teaching and Learning (CTL) Untuk Hasil Belajar Bahasa Indonesia siswa kelas I SD Negeri 012 Pangkalan Baru Kecamatan Siak Hulu, SD Negeri 012 Pangkalan Baru Kecamatan Siak Hulu, Jurnal Pendidikan Guru Sekolah ASSURE model - Learning Theories ETC547 Spring 2011 (google.com)

Damardi, H. (2011). Metode Penelitian Pendidikan. Bandung: Alfabeta

Dewi, P. Y., \& Primayana, K. H. (2019). Effect of learning module with setting contextual teaching and learning to increase the understanding of concepts. International Journal of Education and Learning, 1(1), 19-26.

Imanuel, S. (2015). Kesulitan Belajar IPA Peserta Didik Sekolah Dasar. STKIP Persada Khatulistiwa, Jl Pertamina, Sengkuang, Sintang, Vox Educasi Vol.6 no.2, 109-122.

Karina, R.M., Syafrina, A., \& Habibah, Sy., (2017), Hubungan Antara Minat Belajar Dengan hasil belajar Siswa Dalam Mata Pelajaran IPA Pada Kelas V SDN Garot Geuceu Aceh Besar, Jurnal Ilmiah Pendidikan Guru Sekolah Dasar, FKIP Unsyiah, Vol. 2 No.1 61-77. Sugiyono (2015). Statistika Untuk Penelitian.Bandung: Alfabet

Sukiman, (2012), Pengembangan Media Pembelajaran, Yogyakarta: Pedagogia.

Supriadi, S. (2008). Penggunaan Kartun Matematika Dalam Pembelajaran Matematika. Jurnal Pendidikan Dasar, 2(10).

Wahyu Susiloningsih, (2016), Model Pembelajaran CTL (Contextual Teaching and Learning) dalam Meningkatkan Hasil Belajar Mahasiswa PGSD Pada Matakuliah Konsep IPS Dasar, Jurnal Pedagogis ISSN.2089-3833 Vol.5 No.1 